\title{
Depression and Diabetes in Jimma University Specialized Hospital, Southwest Ethiopia
}

Sisay Dejene ${ }^{1}$, Alemayehu Negash ${ }^{1}$, Kenfe Tesfay ${ }^{1}$, Andrea Jobst $^{2}$ and Mubarek Abera ${ }^{1 *}$

${ }^{1}$ Department of Psychiatry, College of Public Health and Medical Sciences, Jimma University, Jimma, Ethiopia

${ }^{2}$ Department of Psychiatry and Psychotherapy, University of Munich, Germany

\begin{abstract}
Background: Diabetes and depression are a highly prevalent, devastating and disabling condition associated with high morbidity, mortality, and healthcare consumption. Co-existing depression in people with diabetes results in decreased adherence, poor health outcome, higher diabetes complication, decreased quality of life, increased disability and lost productivity with increased risk of death.
\end{abstract}

Objective: The aim of this study was to determine the prevalence and associated factors of depression among patients with diabetes in Jimma University specialized hospital.

Methodology: Hospital based cross-sectional study was conducted from 23 September to 22 November 2012. A face to face interview was conducted using structured questionnaire by trained and experienced health professionals. The participants were selected by using systematic random sampling technique. The data was analyzed by using simple descriptive analysis, binary and multiple logistic regression analysis method. P-value of $<0.05$ was considered statistically significant.

Result: A total of 335 people with diabetes were interviewed. About $124(37 \%)$ and $211(63 \%)$ of the patients were found to have type- 1 and type-2 DM respectively. The prevalence of depression among people with diabetes was $43.6 \%$ (52.7\% among females and $36 \%$ among males). Presence of at least one diabetes complication and older age $>55$ years were found to be independent predictor of depression among people with diabetes.

Conclusion: This study demonstrated that prevalence of depression was high among patient with diabetes. Depression might have severe impact to the course and prognosis of diabetes and should therefore be carefully diagnosed and treated early in the course of illness.

Keywords: Co-morbidity; Depression; Diabetes

Abbreviations: BDI, beck depression Inventory scale; DM, diabetic mellitus; JUSH, Jimma university specialized hospital; MDD, major depressive disorder; SPSS, statistical package for social sciences; USA, United States of America; WHO, World Health Organization

\section{Introduction}

Diabetes mellitus (DM), the commonest endocrine system disorder, is a chronic metabolic disease that occurs when the pancreas is not able to produce enough insulin (Type $1 \mathrm{DM}$ ), or when the body cannot effectively utilize the insulin it produces (Type $2 \mathrm{DM}$ ) [1,2].

According to the international diabetes federation report, the worldwide prevalence of DM has risen dramatically over the past two decades from an estimated prevalence of 30 million cases in 1985 to 177 million in 2000. Based on the current trends, more than 360 million individuals will have diabetes by the year 2030. Diabetes contributes for 4.6 million deaths per year, accounting for $8.2 \%$ of all-causes of global mortality [3]. World Health Organization (WHO) estimated that the number of patients with diabetes in Ethiopia to be 800,000 by the year 2000 , and the number are expected to increase to 1.8 million by 2030 $[2,4]$.

Depression is common in the general population, but physical illness increases the risk for depression and therefore it is very much higher among people with physical illness and is even worse with more severe disease, especially when there is poor social support and other adverse life situation [5]. The average lifetime and 12-month prevalence estimates of DSM-IV major depressive disorder (MDD) among the general population was $14.6 \%$ while it was $25 \%$ to $33 \%$ among people with chronic illness [6,7]. It was also observed that about one-third of individuals with a serious medical condition show symptoms of depression [7].

Depressive disorder is one of the common and devastating psychiatric co-morbidities among people with diabetes. Depressive disorder is characterized by depressed mood, loss of interest or pleasure, feelings of guilt or low self-worth, disturbed sleep or appetite, low energy, and poor concentration. This problem can become chronic or recurrent leading to substantial impairment in an individual's ability to take care of his or her everyday responsibilities; and at its worst, depression can lead to suicide, a tragic fatality associated with the loss of about 850000 lives every year in the world $[4,8]$.

Co-morbidity of both disorders leads to decreased adherence to treatment, poor metabolic control, higher complication rates, decreased quality of life, increased healthcare use and cost, increased disability and lost productivity leading for increased risk of death [9].

*Corresponding author: Mubarek Abera, Department of Psychiatry, College of Public Health and Medical Sciences, Jimma University, Jimma, Ethiopia, Tel: +251(0)913 33 2483; E-mail: abmubarek@yahoo.com

Received April 16, 2014; Accepted May 19, 2014; Published May 27, 2014

Citation: Dejene S, Negash A, Tesfay K, Jobset A, Abera M (2014) Depression and Diabetes in Jimma University Specialized Hospital, Southwest Ethiopia. J Psychiatry 17: 126 doi: 10.4172/Psychiatry.1000126

Copyright: ( 2014 Dejene S, et al. This is an open-access article distributed under the terms of the Creative Commons Attribution License, which permits unrestricted use, distribution, and reproduction in any medium, provided the original author and source are credited 
Though the relationship between depression and diabetes is difficult, the occurrence of depression is increasing rapidly all over the world among patient with diabetes. Several studies suggest that diabetes doubles the risk of depression compared to those without the disorder and the chances of becoming depressed increase as diabetes complications worsen. It negatively affects the course of diabetes and is associated with increased risk of complications. Early screening and treatment of depression helps people with diabetes manage symptoms of both diseases, thus improving the quality of their lives [10].

Therefore this study will be the first in its kind to be conducted in Ethiopia aiming to assess the prevalence, pattern and associated factor of depressive disorder among patient with diabetes in Jimma, Ethiopia, 2012. This finding could provide scientific evidence for policy makers, programmers and service planers to make informed decision that could address the best interests of patient with diabetes leading to better health and quality of life.

\section{Methods and Study Subjects}

\section{Study setting}

The study was conducted at Jimma University Specialized Hospital (JUSH) diabetes clinic. Jimma town is located $352 \mathrm{kms}$ southwest of Addis Ababa, the capital city of Ethiopia. JUSH is one of the biggest and oldest university specialized hospital in the country established in 1923 and is providing service for more than 15 million people in the catchment area. Currently, it is the only teaching and referral hospital in south western part of the country. The hospital has bed capacity of 517 with an approximate 9000 inpatients and 80,000 outpatients per annum. There are a total of 1788 registered patient with diabetes in the diabetes clinic.

\section{Study design and sampling}

Hospital based cross-sectional study design was implemented. The sample size was calculated using single population proportion formula with an assumption of $50 \%$ prevalence of depression among patient with diabetes, $95 \%$ confidence interval, and $5 \%$ degree of precision to get a total sample of 349 patients with. Systematic random sampling technique was used to recruit the study participants. All adult $(\geq 18$ years) patients with diabetes attending follow up care in JUSH diabetic clink were included in the study. But those patients with severe form illness and/or in a state of altered level of consciousness were excluded from the study.

\section{Measurements}

Socio demographic related information was assessed using a structured questionnaire developed by reviewing other related articles. Other independent variables that could affect the occurrence of depression among patient with diabetes were also included to the questionnaire by reviewing other similar studies. The initial English version of the questionnaire was translated to the local language and was translated back to English independently to check for semantic validity.

Beck Depression Inventory Scale (BDI-II) was used to screen for depression among patient with diabetics. BDI-II first was designed as outcome measurement for follow-up cases in drug trial studies, but has been also used as a screening tool for depression in many epidemiological studies in across the world. It was also best validated tool for the screening of depression among patient with diabetes in different countries, cultures and population groups. It consists of 21 questions with a likert scale of 0-3 providing a total score of 63 .
According to the revised version of Beck-II in 1996, the score from 0-13 is considered as normal, $14-19$ as mild, $20-28$ as moderate and $29-63$ as severe depression [11].

\section{Data collection}

The data was collected by a face to face interview method from 23 September 2012 to 22 November 2012 by four trained data collectors who were fluent in the local language. One second degree holder health professional was assigned as supervisors and had checked all the questionnaires for consistency, completeness and quality of the data on a daily basis.

\section{Data quality assurance}

The questionnaire was pre tested on $5 \%$ of the sample size in Jimma hospital to check for understandability and applicability of the instrument. Data collectors and the supervisors were trained for one and half day and frequent follow up was done during the process of data collection. Data were checked and entered into Epi-data for double data entry verification which was then exported to SPSS version 16.0 for analysis.

\section{Data analyses}

The data was edited, cleaned and analyzed using SPSS version 16.0 for windows. The data were checked for its distribution and outliers before analysis. It was processed by using descriptive analysis, including frequency distribution, cross tabulation and summary measures. Tests of association were investigated using $\chi^{2}$ test followed by binary logistic regression. Finally multivariate logistic regression was computed for some of important variables taking from the binary logistic regression model to identify independently associated factors in the final model.

\section{Ethical clearance}

Ethical clearance was secured from the ethical review board of Jimma University College of Public Health and Medical Science. Written informed consent was obtained from each study participant. Individuals who were unwilling to participate from the beginning or any part of the interview were allowed to do so. Privacy and strict confidentiality were maintained during the process of interview. There was no any risk of danger or hazardous procedure putting the participants at harm. Patients found to have severe depression were referred to psychiatry clinic for further assessment and treatment. The authors declare that they have no competing interests.

\section{Result}

\section{Socio-demographic characteristics}

Out of 349 patients with diabetes intended to participate in the study, 335 patients actually responded for the interview making a response rate of $96 \%$. Twelve participants refused to participate claiming that they do not have enough time for the interview; whereas two of the remaining participants were not able to give information because of pain they have been experiencing. Of those actually responded to the study $185(55.2 \%)$ of the participants were males, $252(75.2 \%)$ were married and $41(12.2 \%)$ were single. Regarding the religious affiliation, majority 177 (52.8\%) of the respondents were Muslim and 127 (37.8\%) were Coptic Christians. The mean age and standard deviation (SD) of the participants was $46.5(\mathrm{SD}=15.6)$ years.

About 124 (37\%) and 211 (63\%) patients were found to have type-1 DM and type-2 DM respectively. As to their diabetes medication, all patient with type-I DM were on injectable form (insulin) and majority 


\begin{tabular}{|c|c|c|c|}
\hline $\begin{array}{l}\text { Socio-demographic } \\
\text { characteristics }\end{array}$ & Classification & Frequency & $\%$ \\
\hline \multirow{2}{*}{ Sex } & Male & 185 & 55.2 \\
\hline & Female & 150 & 44.8 \\
\hline \multirow{4}{*}{ Age } & $18-34$ & 83 & 24.8 \\
\hline & $35-44$ & 52 & 15.5 \\
\hline & $45-54$ & 76 & 22.7 \\
\hline & 55 and above & 124 & 37.0 \\
\hline \multirow{3}{*}{ Marital status } & Married & 252 & 75.2 \\
\hline & Single & 41 & 12.2 \\
\hline & Divorced and widowd & 42 & 12.6 \\
\hline \multirow{3}{*}{ Religion } & Orthodox & 127 & 37.8 \\
\hline & Muslim & 177 & 52.8 \\
\hline & Other & 31 & 9.4 \\
\hline \multirow{3}{*}{ Living condition } & Alone & 18 & 5.4 \\
\hline & With family members & 276 & 82.4 \\
\hline & $\begin{array}{l}\text { With people out of family } \\
\text { member }\end{array}$ & 41 & 12.2 \\
\hline \multirow{2}{*}{ Residence } & Rural & 122 & 36.4 \\
\hline & Urban & 213 & 63.6 \\
\hline \multirow{6}{*}{ Educational status } & Illiterate & 88 & 26.3 \\
\hline & Able to read and/ write & 31 & 9.3 \\
\hline & Grade 1-6 & 75 & 22.4 \\
\hline & Grade $7-10$ & 64 & 19.2 \\
\hline & Grade 11-12 & 33 & 9.9 \\
\hline & College diploma+ & 44 & 13.2 \\
\hline \multirow{8}{*}{ Occupation } & Farmer & 106 & 31.6 \\
\hline & Government employed & 68 & 20.3 \\
\hline & House wife & 50 & 14.9 \\
\hline & Retired & 34 & 10.1 \\
\hline & Private employees & 25 & 7.5 \\
\hline & Merchant & 24 & 7.2 \\
\hline & Student & 21 & 6.3 \\
\hline & Unemployed & 7 & 2.1 \\
\hline \multirow{4}{*}{$\begin{array}{l}\text { Average monthly } \\
\text { income }\end{array}$} & $<350$ & 56 & 16.7 \\
\hline & $350-750$ & 89 & 26 \\
\hline & $751-1050$ & 86 & 25.7 \\
\hline & $>1050$ & 104 & 31.0 \\
\hline
\end{tabular}

Table 1: Distribution of study participants by socio-demographic characteristics at JUSH diabetes follow-up clinic, $2012(n=335)$.

of patients with type II DM were on tablet form while 27 (8.1\%) of the patients were on both types of medication (Table 1).

\section{Severity of depression}

The overall prevalence of depression among patient with diabetes according to BDI-II measurement was $146(43.6 \%)$. From the total participants $26.6 \%, 14.3 \%$ and $2.7 \%$ were found to have mild, moderate and severe form of depression two weeks prior to the study period respectively (Table 2).

\section{Socio-demographic factors and depression}

The prevalence of depression was higher in female $79(52.7 \%)$ than male $67(36.2 \%)$. Twenty one (50\%) of retired, 23 (46\%) of house wives, $29(42.6 \%)$ of government employees, 10(41.7\%) of merchants, $44(41.5 \%)$ of farmers, $9(36 \%)$ of private employees, $6(30 \%)$ of students were found to be depressed. Regarding the age distribution of depression, 23 (27.7\%) were in the age group of $18-34,24(46.2 \%)$ were in age group 35-44, 34(44.7\%) were in age group 45-54, and 65 $(52.4 \%)$ were in age group $\geq 55$ years of age which indicates that, the prevalence of depression was higher among elderly groups. Concerning educational status, the prevalence of depression was 47 (53.4\%) for illiterate, $16(51.6 \%)$ for those able to only read and write and $83(38 \%)$ for those who have formal education. The prevalence of depression among those having monthly income of $<350$ and 351-750 Ethiopian birr/month was $57.1 \%$, and $40.4 \%$ respectively, while among those earning 751-1050 and >1050 Ethiopian birr/month was 36\% and $45.2 \%$ respectively.

In the binary logistic regression analysis; Sex (COR: 1.96, 95\% CI (1.263, 3.039)); age (COR: 2.238, 95\% CI (1.081, 4625)); marital status (COR: $2.800,95 \%$ CI $(1.406,5.575)$ ); and khat chewing behavior (COR: $0.480,95 \% \mathrm{CI}(0.270,0.853))$ were found to have statistically significant association with depression among diabetic patients.

\section{Disease and medication related factors}

Among respondents with type I and type II DM, 47 (37.9\%) and $99(46.9 \%)$ of the participants were found to be depressed respectively. When we assess the magnitude of depression related to diabetes medication; $68(39.1 \%)$ of Injectable users, $65(48.5 \%)$ of tablet users, and $13(48.1 \%)$ of combined medication users were found to be depressed. About 66 (37.1\%) of patient with duration of diabetes illness less than five years, $52(48.6 \%)$ with duration of diabetes illness 6-10 yrs, 18(56.2\%) with duration of diabetes illness 11-15 years, 5 (41.7\%) with duration of diabetes illness $16-20$ yrs and $5(83.3 \%)$ with duration of diabetes illness above 20 years were found to be depressed indicating that the prevalence has been increased with duration of illness.

\section{Diabetes related complication and depression}

Among the total respondents, 125(37\%) had visual disturbance, 77 (23\%) had hypertension and $53(15.8 \%)$ had neuropathy, of whom 65(52\%), $37(48.1 \%)$ and 31(58.5\%) were found to have depression respectively. In bi-variate logistic regression, visual disturbance COR: $1.725,95 \%$ CI $(1.103,2.699)$, neuropathy COR: $2.046,95 \%$ CI $(1.128$, $3.713)$ and foot ulcer COR: $6.060,95 \%$ CI $(1.693,21.68)$ were found to have significant association with depression (Table 3).

However, in the final multiple logistic regression analysis controlling for confounders the result revealed that only sex, older age and presence of diabetic complication were found to be independent predictors of depression among diabetic patient. Age $>55$ year have nine times greater odds of having depression than those aged 18-34 year and the odds of having depression was 1.8 times higher in female than male.

\section{Discussion}

The overall prevalence of depression in this study was $43.6 \%$ using BDI-II cut-off point 14 . The prevalence was higher in female than males $(52.7 \%$ vs. $36.2 \%)$ and among divorced or widowed $66.7 \%$ than their counterparts. Regarding the age of participants, there was higher prevalence $(52.4 \%)$ in those aged greater than or equal to 55 year than (27.7\%) in youngster aged 18-24 years. Higher prevalence of depression

\begin{tabular}{|c|c|c|c|c|c|}
\hline \multirow{2}{*}{ Category } & \multicolumn{5}{|c|}{ BDI-II cut-off points for level of depression } \\
\cline { 2 - 6 } & $\begin{array}{c}\mathbf{0 - 1 3} \\
\text { (Normal) }\end{array}$ & $\begin{array}{c}\mathbf{1 4 - 1 9} \\
\text { (Mild } \\
\text { depression) }\end{array}$ & $\begin{array}{c}\mathbf{2 0 - 2 8} \\
\text { (Moderate } \\
\text { depression) }\end{array}$ & $\begin{array}{c}\text { 29-63 } \\
\text { (Severe } \\
\text { depression) }\end{array}$ & $\begin{array}{c}\text { 14-63 (Overall } \\
\text { depression } \\
\text { prevalence) }\end{array}$ \\
\hline Male & $118(35.2 \%)$ & $46(13.7 \%)$ & $18(5.4 \%)$ & $3(0.9 \%)$ & $67(36.2 \%)$ \\
\hline Female & $71(21.2 \%)$ & $43(12.8)$ & $30(8.95)$ & $6(2 \%)$ & $79(52.7 \%)$ \\
\hline Total & $189(56.4 \%)$ & $89(26.6 \%)$ & $48(14.3 \%)$ & $9(2.7)$ & $146(43.6)$ \\
\hline
\end{tabular}

Table 2: Depression classification based on gender and severity in Jimma University Specialized Hospital DM follow up clinic $2012(n=335)$. 


\begin{tabular}{|c|c|c|c|c|c|}
\hline \multirow{2}{*}{$\begin{array}{l}\text { Co-morbid Health } \\
\text { problems }\end{array}$} & \multirow{2}{*}{ Frequency } & \multicolumn{2}{|c|}{ Depression } & \multirow[b]{2}{*}{ P-value } & \multirow[b]{2}{*}{ COR(95\%Cl) } \\
\hline & & Yes (\%) & No (\%) & & \\
\hline \multirow{2}{*}{ Visual disturbance } & Yes125(37.3) & $65(52 \%)$ & $60(48 \%)$ & $0.017^{*}$ & $1.725(1.103,2.699)$ \\
\hline & No $210(62.7)$ & $81(38.6 \%)$ & $129(61.4 \%)$ & - & 1 \\
\hline \multirow{2}{*}{ Neuropathy } & Yes $5(15.8)$ & $31(58.5 \%)$ & $22(41.5 \%)$ & $0.018^{*}$ & $2.046(1.128,3.713)$ \\
\hline & No $282(84.8)$ & $115(40.8 \%)$ & $167(59.2 \%)$ & - & 1 \\
\hline \multirow{2}{*}{ Hypertension } & Yes $\quad 77(23)$ & $37(48.1 \%)$ & $40(51.9 \%)$ & 0.368 & $1.264(0.759,2.107)$ \\
\hline & No $258(77)$ & $109(42.2 \%)$ & $149(57.8 \%)$ & - & 1 \\
\hline \multirow{2}{*}{ Nephropathy } & Yes $47(14)$ & $24(50 \%)$ & $24(50 \%)$ & 0.334 & $1.352(0.733,2.495)$ \\
\hline & No $288(86)$ & $122(42.5 \%)$ & $165(57.5 \%)$ & - & 1 \\
\hline \multirow{2}{*}{ Skin infection } & Yes 27(8.1) & $14(51.9 \%)$ & $13(48.1 \%$ & $0 . .368$ & $1.436(0.653,3.157)$ \\
\hline & No 308(91.9) & $132(42.9 \%)$ & $176(57.1 \%)$ & - & 1 \\
\hline \multirow{2}{*}{ Impotence } & Yes 4(13.1\%) & $23(52.3 \%$ & $21(47.7 \%)$ & 0.214 & $1.496(0.792,2.825)$ \\
\hline & No $291(86.9 \%)$ & $123(42.3 \%)$ & $168(57.7 \%$ & - & 1 \\
\hline
\end{tabular}

Statistically significant*

Table 3: Association of co-morbid health problems with depression among patients with DM JUSH diabetic follow-up clinic, September- October 2012.

(61.8\%) was also observed among retired patients, followed by unemployed and house wife (50\% and $46 \%)$ participants respectively. Regarding the prevalence of depression based on duration of diabetes illness, about $37.1 \%$ with illness duration of less than five years were found to have depression compared to $83.3 \%$ of patient with duration of illness above 20 years which clearly indicates that the prevalence has been increased with duration of illness. The prevalence of depression in type II DM was (46.9\%), in diabetes related complication like foot ulcer was $(81.2 \%)$, visual disturbance was $(52.0 \%)$ and impotence was $(52.3 \%)$.

The prevalence of depression (43.6\%) from this study was completely consistent with the findings from Iran and Pakistan [12,13]. In these two studies factors significantly associated with depression were being in age group $>50$ years, female sex, low income, not living with spouse, being married, duration of illness $>5$ years and having one or more complications of diabetes $[12,13]$. However in our study age $>50$ years, age group 35-44 and 45-54 years, chat chewing, duration of diabetes illness between 11-15 years, female sex, divorce or widowed were found to have significant association in bi-variate analysis but only sex, age, and presence of complication were independently associated with depression. In addition the protective factor, age and sex categories in the above two studies were completely consistent with our findings. In contrast to the above two studies, being married was a protective factor for depression in this study which was actually consistent with other studies in which cultures social, economic and emotional support of the husband plays a crucial role in preventing the occurrence of depression $[14,15]$.

The total prevalence of depression (43.6\%) in our study was a bit higher than the studies done in Bangladesh (34.8\%), Greek (33.9\%) and Bahrain (33.3\%) $[14,16,17]$. The difference could be due to the inclusion of only patients with type II DM and exclusion of patients having overt macro vascular complication in Greek's study and use of depression screening tool other than BDI in the Bangladesh's study. While in the study conducted in Bahrain, the cut-off point of 16 or more from BDI scale was used to define depression, which is higher than the cut-off point used in this study. The prevalence in this study was still much higher than a study conducted in Ireland [18] but consistent with the Indian study [19]. The higher prevalence of depression in developing countries could be due to higher level of inequalities, health care inequities, low quality of diabetic care, social insecurity, lower level of education poverty and financial difficulties and other forms of economic stressors than developed one [20]. In this study, female sex, retired people and house wife were found to be significantly associated with depression [14].

A study conducted in Amsterdam, the result revealed that one third of patients with type I DM and $37 \%$ of patients with type II DM were depressed [21] which was in agreement with our study in that it was higher among type II DM. This similarity could be explained by the path physiological similarities of DM across countries. The prevalence of depression in Amsterdam for male and female patients with type I DM were $25 \%$ and $30 \%$ respectively which were lower than ours; $28 \%$ in male and $53 \%$ in female. The same is true regarding type II DM which was 35\% and 38\% for male and female in Amsterdam's study, whereas it was $41.8 \%$ and $52.5 \%$ for male and female respectively in our study. The difference based on sex with specific type of DM could be due to gender difference in both social and economic related activities among countries in comparison and hormonal difference among sex. The higher prevalence of depression in our study may be attributed to lower socioeconomic status which is further complicated by male dominated resource distribution in Ethiopia. Therefore, comparability between the studies might be delimited by cultural factors as well.

A study conducted in Bosnia Herzegovina in 2007 among patient with diabetes the prevalence of depression was 36\% (32\% in male and $39 \%$ in female) and it showed that the higher prevalence was in the age group 51-80 years which was a consistent finding to our study [22].

A study conducted in South Carolina, USA, to assess the independent factors associated with major depressive disorder in a national sample of individuals with diabetes, respondents scored for depression were more likely to have duration of diabetes illness 5 or more years and major diabetes complications; which was in agreement to this study [23]. Moreover, a study in Nigeria the result was much lower $19.4 \%$ compared to our finding; the difference could be due to the screening tools and the sample size and also due to high magnitude of khat use (a psycho-stimulant substance) in our study area whose withdrawal lead to depressive feeling [24].

\section{Limitations}

Due to lake of sophisticated screening tests, time and budget constraints, diabetes complications addressed in this study were not confirmed by respective specialists instead only by patient's subjective response of complication was used. As the study was a simple crosssectional study design, it was impossible to know the direction of cause and effect relationship of diabetic and depression. It also lacks control or comparison group. 
Citation: Dejene S, Negash A, Tesfay K, Jobset A, Abera M (2014) Depression and Diabetes in Jimma University Specialized Hospital, Southwest Ethiopia. J Psychiatry 17: 126 doi: 10.4172/Psychiatry.1000126

Page 5 of 5

\section{Conclusion and Recommendation}

The prevalence of depression in this study was found to be high and most of the study subjects suffered from milder form of depression which is actually easily treatable with minimal cost expense. It is recommend that strong referral linkage between diabetes and psychiatry clinic has to be set functional and further integration of mental health care in to diabetes clinic has to be considered. Continuous health information, education and communication towards raising awareness about the possibilities of co morbidities and early sign and symptoms of depression has to be delivered for patients with diabetes in regard to promoting early detection and treatment of the co morbidities for better health and quality of life. Researchers for future could repeat the study with a comparison or control group to see the difference.

\section{Authors' contributions}

$\mathrm{SD}, \mathrm{AN}, \mathrm{KT}, \mathrm{AJ}$ and MA all contributed to the study design, SD conducted the study, supervised in the field by AN, KT and MA. SD, AN, KT, AJ and MA analyzed the data. SD wrote the first draft of the manuscript. All authors contributed to interpretation of the study findings.

\section{Acknowledgements}

The authors would like to acknowledge the participants for taking the time to participate in the study. We also like to acknowledge Center for International Health Ludwig-Maximilians-University, Munich Germany for their technical and expertise support throughout the process of the research activities.

\section{Competing interests}

The authors declare that they have no competing interests.

\section{References}

1. Charbonnel B (2005) What a psychiatrist needs to know about diabetes European psychiatry 20: 330-4.

2. Anthony D, Alvin L (2008) Kasper F. Diabetes mellitus. In: Harrison, Brauwnwald Kasper(eds) Harrison's principles of internal medicine, 17th edition, The McGraw Hill Companies, Inc 2275-304.

3. International Diabetes Federation (2011) The IDF Diabetes Atlas 5th edition: Brussels: International Diabetes Federation.

4. Paula M Trief (2007) depression in elderly diabetes patients: Diabetes Spectrum. 20: 71-75.

5. Wilhelm K, Mitchell P, Slade T, Brownhill S, Andrews G (2003) Prevalence and correlates of DSM-IV major depression in an Australian national survey. J Affect Dis $75: 155-162$

6. Evelyn B, Laura H, Irving H, Nancy A, Jordi A, Giovanni D, et al. (2011) Crossnational epidemiology of DSM-IV major depressive episodes. BMC Medicine.

7. Cynthia H (2005) Depression caused by chronic illness. MedicineNet.com.

8. Robert B, Andrew J, Stephen C, Arleen FB, Usha S, Shou-En Lu,et al. (2010)
Correlates of depression among people with diabetes: the Translating Research into action for diabetes (TRIAD) study. Primary care diabetes 215-222

9. Andrea A, Mindy L, Linda G, Cheryl R. Dennison, Mindy L (2009) Depression as Co-morbidity to Diabetes: implications for Management. JNP 5: 525-529.

10. Ryan J, Bakenneth E, Ray E, Patrick J Lustman (2001) the prevalence of comorbid depression in adults with diabetes: Diabetes care 24: 1069-1078.

11. Beck AT, Steer RA, Ball R, Ranieri W (1996) Comparison of Beck Depression Inventories -IA and -II in psychiatric outpatients. Journal of Personality Assessment 67: 588-97.

12. Marin F, Hardy P, Lepine J (1995) Six-month and lifetime prevalence of psychiatric disorders in patients with diabetes mellitus. Euro psychiatry 10: 245-249.

13. Pouwer F, Geelhoed P, Duijvestijn H, Bazelmans L (2010) Education and psychological aspects: prevalence of co- morbid depression is high in outpatients with Type 1 or Type 2 diabetes mellitus: Results from three out-patient clinics in the Netherlands. Diabetic Medicine 27: 217-224.

14. Jose F, Tellez Z, Mario H (2002) Risk factors associate with depression in patients with Type 2 Diabetes Mellitus. Archives of Medical Research 33: 53-60.

15. Leonard E, Simpsonph D, Deyi Z (2002) Co-morbid depression is associated with increased Health Care Use. 25: 464-470.

16. Nicole G, Janet K., Snell B., Kim M, Gregory K (2002) Prevalence and correlates of depression in individuals with and without type 1 diabetes. Diabetes care 25 : 464-470.

17. Wayne K, Michael V, Paul C, Joan R, Elizabeth L, et al. (2004) Behavioral and clinical factors associated with depression among individuals with diabetes. Diabetes Care 27: 914-920.

18. Alexios S, Athanasia P, Ourania A, Anthi K, Aristofanis G, et al. (2008) Prevalence of depressive symptoms among non insulin treated Greek type 2 diabetic subjects 1011

19. Shahrakivahed A, Moushtagh Z, Firozkohi M, Jahantigh M (2012) Frequency and severity of depression in diabetic patients referred to diabetes center of zabol. Inter disciplinary Journal of Contemporary Research in Business. 4: 935 41.

20. Yekta Z, Pourali R, Yavarian R (2010) Behavioral and clinical factors associated with depression among individuals with diabetes. EMHJ 16: 286-291.

21. Amit R, Ethiraj D, Anil B, Sandeep G, Pramil T (2010) Prevalence \& determinants of depression in type 2 diabetes patients in a tertiary care. Indian J Med Res 132:195-200

22. Leonard E, Charles E (2010) Diabetes and depression Global perspectives. Diabetes research and clinical practice 87: 302-312.

23. Richard R (2001) Psychological Issues and Treatmentsfor People with Diabetes John Wiley \&Sons.Inc. J Clin Psychol 57:457-478.

24. Coker AO, Ohaeri J, Lawal R, Orija OB (2000) Specific psychiatric morbidity among diabetics at a Nigerian general hospital. East African medical journal 77: $42-45$. 